Supporting Information

\title{
Polymer-DNA molecular net for selective transportation of target biomolecules and inhibition of tumor growth
}

Jihyun Lee, ${ }^{\dagger, \S}$ Yeong Mi Lee, ${ }^{\dagger, \S}$ and Won Jong Kim ${ }^{*}+, \S$

${ }^{\dagger}$ Center for Self-assembly and Complexity, Institute for Basic Science (IBS), Pohang 37673, Republic of Korea

${ }^{\S}$ Department of Chemistry, Pohang University of Science and Technology (POSTECH), Pohang 37673, Republic of Korea

KEYWORDS artificial molecular net, polymer-DNA conjugate, DNA structure, anti-tumor therapy, rolling cycle amplification 


\section{Materials}

$40 \%$ acrylamide solution (Sigma), $2 \%$ N,N'-methylenebisacrylamide solution (Sigma), 2 hydroxyethyl methacrylate (Aldrich, $\geq 99 \%$ ), 2-hydroxy-2-methylpropiophenone (Aldrich, $97 \%$ ), N,N,N',N'-tetramethylethylenediamine (TEMED, Sigma, BioReagent, suitable for electrophoresis, $99 \%$ ), ammonium persulfate (APS, Sigma, for molecular biology, for electrophoresis, $\geq 98 \%$ ), Tris- $\mathrm{HCl}$, adenosine 5'-triphosphate (ATP) disodium salt hydrate (Sigma), thymidine 5'-triphosphate (TTP) sodium salt (Sigma, $\geq 96 \%$ ), cytidine 5'triphosphate (CTP) disodium salt (Sigma, $\geq 95 \%$ ), guanosine 5'-triphosphate (TTP) sodium salt hydrate (Sigma, $\geq 95 \%$ ) and SYBR ${ }^{\circledR}$ green I (Invitrogen) were used as received. All sequences of HPLC purified oligonucleotides (ODNs), DNA PrepMateTM-II and AccuPrep® genomic DNA extraction kit were purchased from Bioneer (Daejeon, South Korea). The ODNs sequences are listed in Table S1-S4. CircLigaseTM ssDNA Ligase (Epicentre Biotechnologies, Madison, WI), Exonuclease I (New England Biolabs, Beverly, MA), Exonuclease III (New England Biolabs, Beverly, MA), Ф29 DNA polymerase (New England Biolabs, Beverly, MA), dNTP mix (Promega, Madison, WI) and recombinant human vascular endothelial growth factor-165 (BioLegend, San Diego, CA) were also purchased.

\section{Experimental section}

Characterization of spherical PD-mn. The efficiency of DNA conjugation in PD-mn was measured by absorbance at $260 \mathrm{~nm}$ utilizing UV-VIS spectrometer (Shimadzu Co., UV-2550). The confirmation of conjugated DNA in PD-mn was analyzed by SYBR Green ${ }^{\circledR}$ I staining process which could be intercalated with DNA selectively and shows green fluorescence under UV illuminator (UNOK-800, Gel manager system) or Davinch Western Imaging System (Davinch-K, Younghwa Science, Korea). Also polyacrylamide gel electrophoresis 
(PAGE) analysis was conducted to confirm the DNA conjugation in PD-mn. $10 \mu \mathrm{L}$ of ssDNA or dsDNA were run on the $13 \%$ or $18 \%$ of polyacrylamide gel for 60,100 or 120 min at 100 V using TBE (Tris/borate/EDTA) buffer as running buffer. Denatured PAGE was also prepared utilizing $13 \%$ of polyacrylamide gel and $8 \mathrm{M}$ of urea, and run for $120 \mathrm{~min}$ at $100 \mathrm{~V}$ using TBE buffer. The DNA migration was observed by SYBR Green I ${ }^{\circledR}$ staining method, followed by UV illumination. The monochrome images were obtained by Davinch Western Imaging System, and fluorescence images were obtained by UV illuminator. The cross sectional fluorescence image of PD-mn was obtained by UV illuminator after treatment of PD-mn with complementary FAM-cDNA-containing solution for various time.

Reusability test of spherical PD-mn. The PD-mn was treated with TAMRA-cpDNAcontaining solution for hybridization with Acryd-ATP-DNA of PD-mn and TAMRA-cpDNA through diffusion process. Captured ATP by PD-mn was released by washing the PD-mn, in which the fluorescence of PD-mn was returned into initial state. The washed PD-mn was treated again with TAMRA-cpDNA-containing solution, and this process was repeated. The fluorescence was checked in each step.

DNA circularization and RCA test by spherical PD-mn. The PD-mn conjugated with Acryd-DNA and Acryd-ATP-DNA was utilized for DNA circularization enzymatic reaction. The prepared PD-mn was incubated with both cplDNA and ATP-contained solution. After washing PD-mn to prevent non-specific interaction with cplDNA and ATP, cplDNA and ATP were released into target buffer solution which contained pIDNA and CircLigaseTM ssDNA Ligase by temperature control. According to the CircLigaseTM protocol, the circularized plDNA was obtained. 100 pmole of dsDNA (phosphorylated linear DNA (Circ_cVEGF, Circ_cSc) and Primer) was incubated with $100 \mathrm{U}$ of CircLigaseTM ssDNA Ligase for $1 \mathrm{~h}$ at $60^{\circ} \mathrm{C}$ in $20 \mu \mathrm{L}$ of provided reaction buffer (50 mM MOPS (pH 7.5), $10 \mathrm{mM} \mathrm{KCl,} 1 \mathrm{mM}$ dithiothreitol) with $2.5 \mathrm{mM} \mathrm{MgCl} 2$ and $50 \mu \mathrm{M}$ ATP. After CircLigase inactivation process at 
$80^{\circ} \mathrm{C}$ for $40 \mathrm{~min}$, the resultant solution was gradually cooled down to $4^{\circ} \mathrm{C}$. To remove remaining linear ssDNA templates, the solution was treated with $20 \mathrm{U}$ of Exonuclease I and $100 \mathrm{U}$ of Exonuclease III and incubated at $37.5^{\circ} \mathrm{C}$ for $2 \mathrm{~h}$. Then incubated at $80^{\circ} \mathrm{C}$ for $40 \mathrm{~min}$ for enzyme inactivation followed by gradual cooling down to room temperature. The circular DNA was checked by gel electrophoresis after purified by DNA PrepMateTM-II, and the concentration of circular DNA was determined by measuring absorption at $280 \mathrm{~nm}$. All the used DNAs information is shown in Table. S3. Utilizing circularized plDNA containing solution, rolling circle amplification (RCA) reaction was also conducted by $\Phi 29$ DNA polymerase and buffer condition under $30^{\circ} \mathrm{C}$ as RCA protocol. Purified circular DNA was hybridized with AAm-DNA (AAm_VEGF, AAm_Sc) in buffer solution (50 mM Tris-HCl (pH 7.5), $10 \mathrm{mM} \mathrm{MgCl}_{2}, 4 \mathrm{mM}$ dithiothreitol, $\left.10 \mathrm{mM}\left(\mathrm{NH}_{4}\right)_{2} \mathrm{SO}_{4}\right)$ by annealing at $90^{\circ} \mathrm{C}$ for 5 min, and cooled down to room temperature. 20 pmole of the hybridized DNA were treated with $10 \mathrm{U}$ of $\Phi 29 \mathrm{DNA}$ polymerase at $30^{\circ} \mathrm{C}$ for $1 \mathrm{~h}$ in buffer condition $(50 \mathrm{mM}$ Tris- $\mathrm{HCl}(\mathrm{pH}$ 7.5), $10 \mathrm{mM} \mathrm{MgCl} 2,4 \mathrm{mM}$ dithiothreitol, $10 \mathrm{mM}\left(\mathrm{NH}_{4}\right)_{2} \mathrm{SO}_{4}, 0.2 \mathrm{mg} / \mathrm{mL}$ bovin serum albumin, $40 \mathrm{mM}$ dNTP). After $\Phi 29$ DNA polymerase inactivation process at $90^{\circ} \mathrm{C}$ for $30 \mathrm{~min}$, remaining solution was gradually cooled down to room temperature and stored at $-20^{\circ} \mathrm{C}$ until use.

Each step was confirmed with denatured PAGE or agarose gel electrophoresis analysis.

Similarly, P-aApt or P-aSc sheets conjugated with either Acryd-VEGF or Acryd-Sc were also tested following similar procedure. The information of DNA sequence is shown in Table S4. The VEGF aptamer sequence was utilized reported in literature. ${ }^{1}$

VEGF elimination test by P-aApt sheet in vitro. HepG2 cells (Human hepatoma cells) were cultured at T-75 flask (Corning) in Dulbecco's modified Eagle's medium (DMEM, Hyclone) supplemented with $10 \%$ of fetal bovin serum (FBS, Hyclone), $1 \%$ of penicillin-streptomycin (Gibco) at $37^{\circ} \mathrm{C}$ with $5 \% \mathrm{CO}_{2}$ in a $95 \%$ humidified incubator. For the VEGF elimination test 
from cell-secreted proteins, cells were seeded onto 24 -well culture plates at a density of $1 \mathrm{x}$ $10^{5}$ cells/well and incubated in the medium for 1 day. After gentle washing with DPBS, 200 $\mu \mathrm{L}$ of serum-free DMEM with no glucose, no glutamine, no phenol red (Gibco) was added into each well and incubated for 1 day. The conditioned medium was collected and centrifuged to remove floating HepG2 cells. The remained medium was purified by Amicon Ultra-0.5 centrifugal filters (Millipore) for obtaining from proteins having molecular weight range of $30 \mathrm{kDa}$ to $50 \mathrm{kDa}$ and stored at $-20^{\circ} \mathrm{C}$. To verify the selective capturing property for VEGF by P-aApt sheet with heterogeneous solution in vitro, the VEGF capture procedures were conducted by following same protocols.

Immunohistochemistry and histology analysis. The tumor were excised and fixed in $10 \%$ neutral buffered formalin for $48 \mathrm{~h}$ and embedded in paraffin and sequentially sectioned at 4 mm using a Finesse ME microtome. Tumor sections were stained with hematoxylin and eosin (H\&E) for the assessment of tumor regression. Images were obtained by a microscopy (Nikon eclipse 80i, USA) with 10x magnification located at the Pohang Center for Evaluation of Biomaterials (Pohang Technopark).

For immune-histochemical staining with CD-31, the tumor sections embedded in paraffin cut at $4 \mathrm{~mm}$ thickness were firstly treated with blocking solution $(5 \%(\mathrm{w} / \mathrm{v})$ of BSA in DI-water) to avoid non-specific binding. After several times washing with PBS for $15 \mathrm{~min}$, the primary antibody was applied for $1 \mathrm{~h}$ at room temperature. Secondary antibody conjugated to goat anti-rabbit $\operatorname{lgG}-\mathrm{FITC}$ was treated for $1 \mathrm{~h}$. Finally sections on coverslip were mounted in DAPI mounting medium to see the cell nuclei and stored in dark condition at $4^{\circ} \mathrm{C}$. Fluorescent images were obtained by utilizing confocal laser scanning microscope (Modified Zeiss Axio Observer, Z1 epi-fluorescence microscope) with 40 x magnification.

Table S1. Names and sequences of the DNAs. The 5' end modifications are indicated by bracket. The mismatched sequences are indicated by underline. The DNA used in DNA 
capture experiment is arbitrary DNA sequence, and the DNA used in ATP capture is ATP aptamer sequence.

\begin{tabular}{|c|c|c|c|}
\hline No. & Name & $\begin{array}{l}\text { Sequence } \\
\left(5^{\prime}-3^{\prime}\right)\end{array}$ & $\begin{array}{l}\text { Length } \\
\text { (nts) }\end{array}$ \\
\hline 1 & $\begin{array}{l}\text { Acryd-DNA } \\
\text { (Probe DNA) }\end{array}$ & 5'- [Acrydite] TTTT GGA GTG GTG AGG -3' & 16 \\
\hline 2 & $\begin{array}{l}\text { cpDNA } \\
\text { (competitor DNA) }\end{array}$ & 5'- СCT CAC CAC -3' & 9 \\
\hline 3 & $\begin{array}{l}\text { FAM-cDNA } \\
\text { (FAM-conjugated DNA) }\end{array}$ & 5'- [FAM] CCT CAC CAC TCC -3' & 12 \\
\hline 4 & $\begin{array}{l}\text { TAMRA-smDNA } \\
\text { (TAMRA-conjugated } \\
\text { single mismatch DNA) }\end{array}$ & 5 '- [TAMRA] CCT TAC CAC TCC -3' & 12 \\
\hline 5 & $\begin{array}{l}\text { TAMRA-scDNA } \\
\text { (TAMRA-conjugated } \\
\text { scramble DNA) }\end{array}$ & 5'- [TAMRA] TTC GTA ATT CAG -3' & 12 \\
\hline 6 & FAM-cpDNA & $5^{\prime}-[\mathrm{FAM}] \mathrm{CCT}$ CAC CAC -3' & 9 \\
\hline 7 & cDNA & 5'- CCT CAC CAC TCC -3' & 12 \\
\hline 8 & smDNA & 5'- CCT TAC CAC TCC -3' & 12 \\
\hline 9 & scDNA & 5'- TTC GTA ATT CAG -3’' & 12 \\
\hline 10 & $\begin{array}{l}\text { Acryd-ATP-DNA } \\
\text { (Acrydite-conjugated } \\
\text { ATP aptamer DNA) }\end{array}$ & $\begin{array}{l}\text { 5'- [Acrydite] TTTT AAC CTG GGG GAG TAT TGC } \\
\text { GGA GGA AGG T -3' }\end{array}$ & 32 \\
\hline 11 & TAMRA-cpDNA & 5'- [TAMRA] ACC TTC CTC CGC AA -3' & 14 \\
\hline 12 & ATPcpDNA & 5'- ACC TTC CTC CGC AA -3' & 14 \\
\hline
\end{tabular}


Table S2. Names and sequences of the DNAs used in test of captured target DNA. The 5' end modifications are indicated by bracket. The target DNA is arbitrary DNA sequence. 


\begin{tabular}{|c|c|c|c|}
\hline No. & Name & $\begin{array}{l}\text { Sequence } \\
\left(5^{\prime}-3^{\prime}\right)\end{array}$ & Length \\
\hline 1 & Acryd-cDNA & 5'- [Acrydite] TTTT CCT CAC CAC TCC -3' & 16 \\
\hline 2 & target DNA & 5'- GGA GTG GTG AGG -3' & 12 \\
\hline 3 & A & 5'- AGC TCC ACT CTG AGC T -3' & 16 \\
\hline 4 & B & 5'- AGC TGC ACT CTT GCA GCT -3' & 18 \\
\hline 5 & C & 5'- AGC TGC ACT CTT GTC TCA GCT -3' & 21 \\
\hline 6 & D & 5'- AGC TGC ACT CTT GTC TGG CAG CT -3' & 23 \\
\hline 7 & E & 5'- AGC TGC ACT CTT GTC TGG AAG CAG CT -3' & 26 \\
\hline 8 & F & 5'- GTC CGT AAT AAA GCA AAT TAA GGT GAC -3' & 27 \\
\hline 9 & G & 5'- GGA GCT GCA CTC TTG TCT GGA ACA GCT CC -3' & 29 \\
\hline 10 & $\mathrm{H}$ & $\begin{array}{l}\text { 5'- TGG AGC TGC ACT CTT GTC TGG AAC AGC TCC A - } \\
3 \text {, }\end{array}$ & 31 \\
\hline
\end{tabular}

Table S3. Names and sequences of the DNAs used in RCA test of captured target DNA and ATP. The 5' end modifications are indicated by bracket. The matched sequences are indicated 
by bold or underline. The Acryd-DNA is partial complementary sequence of cplDNA, and the Acryd-ATP-DNA is the ATP aptamer sequence.

\begin{tabular}{|c|c|c|c|}
\hline No. & Name & $\begin{array}{l}\text { Sequence } \\
\left(5^{\prime}-3^{\prime}\right)\end{array}$ & $\begin{array}{l}\text { Length } \\
\text { (nts) }\end{array}$ \\
\hline 1 & Acryd-DNA & 5'- [Acrydite] TTTT AAA CCA CAC GAT CCT -3' & 19 \\
\hline 2 & $\begin{array}{l}\text { Acryd-ATP-DNA } \\
\text { (Acrydite- } \\
\text { conjugated ATP } \\
\text { aptamer) }\end{array}$ & $\begin{array}{l}\text { 5'- [Acrydite] TTTT AAC CTG GGG GAG TAT TGC } \\
\text { GGA GGA AGG T -3' }\end{array}$ & 32 \\
\hline 3 & $\begin{array}{l}\text { cplDNA } \\
\text { (Complementary } \\
\text { padlock DNA) }\end{array}$ & 5'- TAG TTA GGA TCG TGT GGT TT -3' & 20 \\
\hline 4 & $\begin{array}{l}\text { PIDNA } \\
\text { (Padlock DNA) }\end{array}$ & 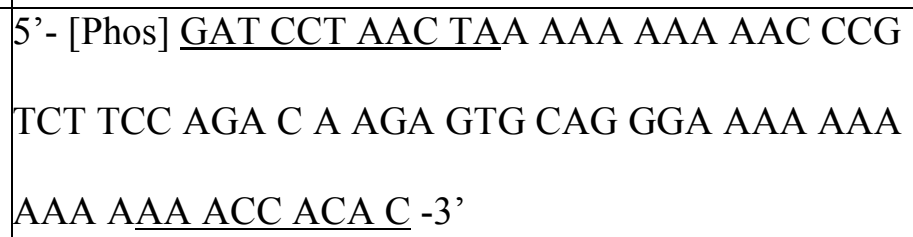 & 66 \\
\hline
\end{tabular}


Table S4. Names and sequences of the DNAs used in P-aApt and P-aSc sheets preparation.

The 5' end modifications are indicated by bracket. The Acryd-VEGF is the human VEGF aptamer sequence.

\begin{tabular}{|c|c|c|c|c|}
\hline No. & \multicolumn{2}{|l|}{ Name } & Sequence $\left(5^{\prime}-3^{\prime}\right)$ & $\begin{array}{l}\text { Length } \\
\text { (nts) }\end{array}$ \\
\hline 1 & \multicolumn{2}{|l|}{ Primer } & 5'-TTAGGATCGTGTGGTT-3' & 16 \\
\hline 2 & \multicolumn{2}{|c|}{$\begin{array}{l}\text { Circ-cVEGF } \\
\text { (Circularize- } \\
\text { complementary } \\
\text { VEGF aptamer) }\end{array}$} & $\begin{array}{l}\text { 5'-[PHOS] } \\
\text { GATCCTAACTAAAAAAAAAACCCTGCACTCTTG } \\
\text { TCTGGAAGACGGGAAAAAAAAAAAAAACCAC } \\
\text { AC-3' }\end{array}$ & 66 \\
\hline 3 & \multicolumn{2}{|c|}{$\begin{array}{l}\text { Circ-cSc } \\
\text { (Circularize- } \\
\text { complementary } \\
\text { scramble) }\end{array}$} & $\begin{array}{l}\text { 5'-[PHOS] } \\
\text { GATCCTAACTAAAAAAAAAAATGAAACAAAAT } \\
\text { TCGGTTCCATAATAAAAAAAAAAAAAAACCAC } \\
\text { AC-3' }\end{array}$ & 66 \\
\hline 4 & \multicolumn{2}{|c|}{$\begin{array}{l}\text { Acryd-VEGF } \\
\text { (Acrydite-modified } \\
\text { VEGF aptamer) }\end{array}$} & $\begin{array}{l}\text { 5'- } \\
\text { [Acrydite]TTTTCCCGTCTTCCAGACAAGAGTGCA } \\
\text { GGG-3' }\end{array}$ & 30 \\
\hline 5 & $\begin{array}{l}\text { Acryd-Sc } \\
\text { (Acrydite- } \\
\text { modified } \\
\text { scramble) }\end{array}$ & \multicolumn{2}{|r|}{$\begin{array}{l}5 '- \\
\text { [Acrydite]TTTTTATTATGGAACCGAATTTTGTTTCAT-3', }\end{array}$} & 30 \\
\hline
\end{tabular}


(A)

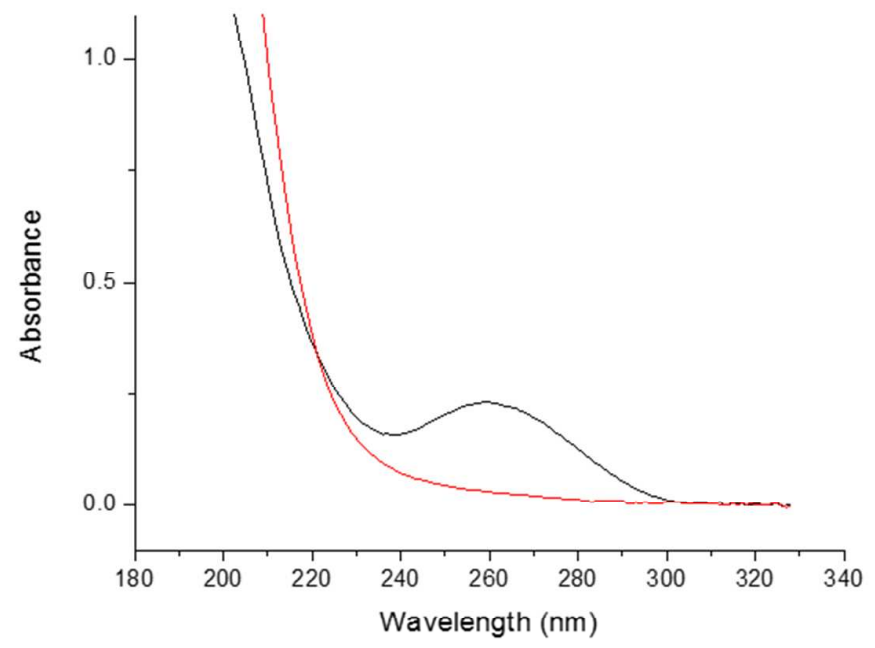

(B)

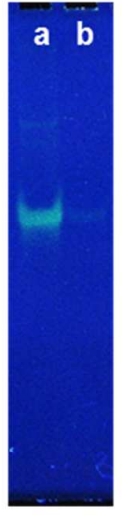

(C)

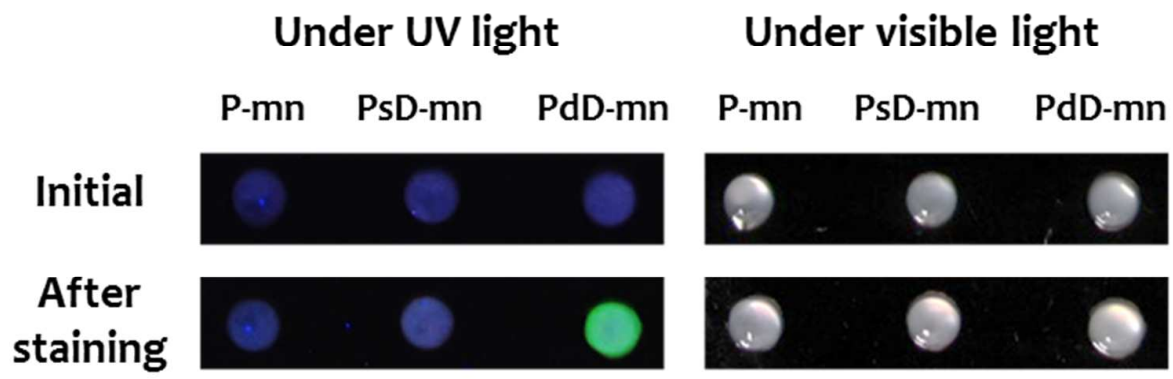

(D)

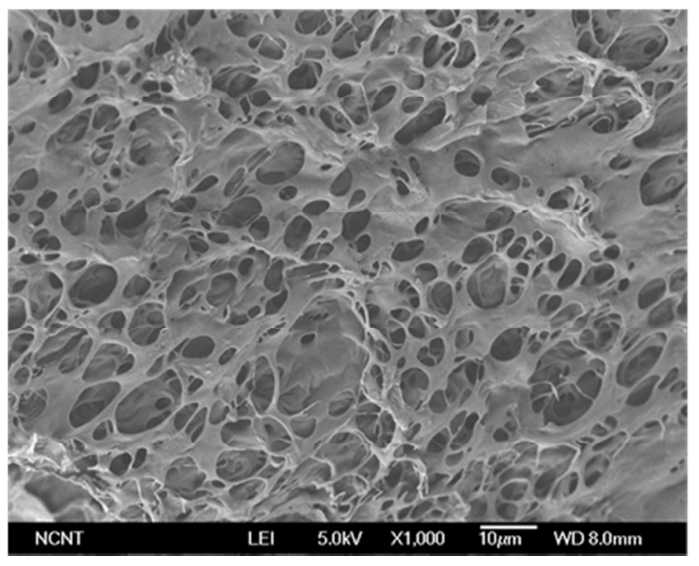

Figure S1. Preparation and characterization of PD-mn. (A) UV absorption spectra of AcrydDNA $(1.86 \mu \mathrm{M})$. Initial absorbance of Acryd-DNA was indicated as black line, and remained Acryd-DNA after polymerization was observed as red line. (B) The PAGE analysis for initial Acryd-DNA (lane a), and remained Acryd-DNA (lane b). (C) Verification of DNA conjugation with polymer utilizing SYBR Green ${ }^{\circledR}$ I staining assay. By incubation of each 
molecular net with SYBR Green ${ }^{\circledR}$ I solution, only PD-mn showed high fluorescence increment under UV illumination because of specific staining of dsDNA by SYBR Green ${ }^{\circledR}$ I. The fluorescence increment factor was calculated as $\left(\mathrm{I}_{\mathrm{t}}-\mathrm{I}_{0}\right) / \mathrm{I}_{0} \times 100, \mathrm{I}_{0}$ as fluorescence intensity at before treatment and $I_{t}$ as fluorescence intensity at after treatment. The fluorescence increment of PdD-mn (conjugation with dsDNA (Acrdy-DNA and cDNA)) was calculated using $\mathrm{I}_{0}=45.1$ and $\mathrm{I}_{\mathrm{t}}=187.4$. Also the fluorescence increment of PsD-mn (conjugation with ssDNA (Acryd-DNA)) was calculated using $\mathrm{I}_{0}=37.5$ and $\mathrm{I}_{\mathrm{t}}=66.1$. All the fluorescence intensity were measured by Image J software program. (D) The SEM (scanning electron microscope) image of PD-mn. The range of pore size is around 1-15 $\mu \mathrm{m}$.

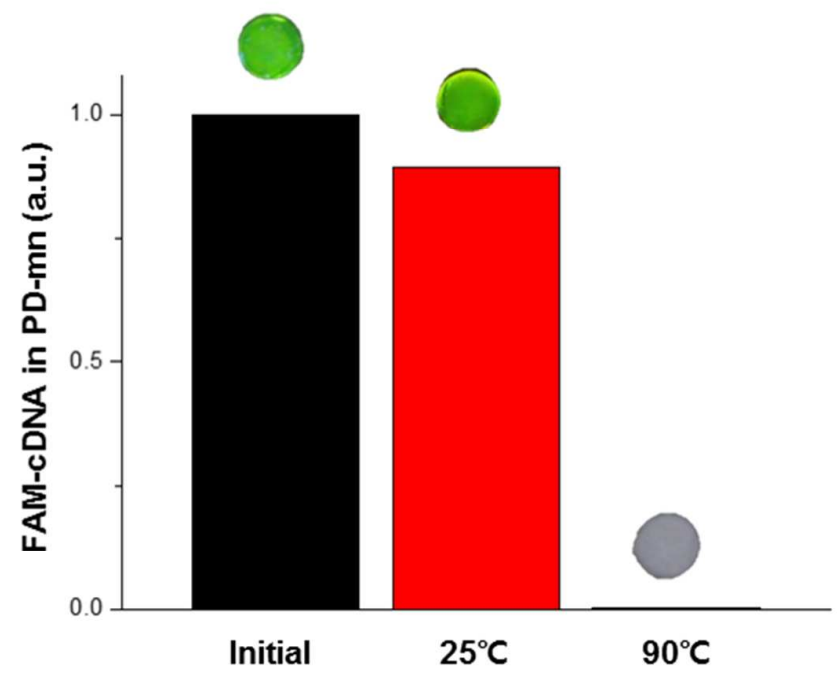

Figure S2. Temperature-mediated release of target molecules from PD-mn. FAM-cDNA was hybridized to PD-mn, and then the release of FAM-cDNA from PD-mn was monitored by fluorescence at different temperatures. Y-axis was converted from the fluorescence intensity of FAM-cDNA to relative amounts of FAM-cDNA. The initial amount of FAM-cDNA was set by 1.000 (black bar), the amount of FAM-cDNA after washing with $25^{\circ} \mathrm{C}$ of DI-water was measured as 0.892 (red bar), and the amount of FAM-cDNA after washing with $90^{\circ} \mathrm{C}$ of DI-water was measured as 0.003 (blue bar). 


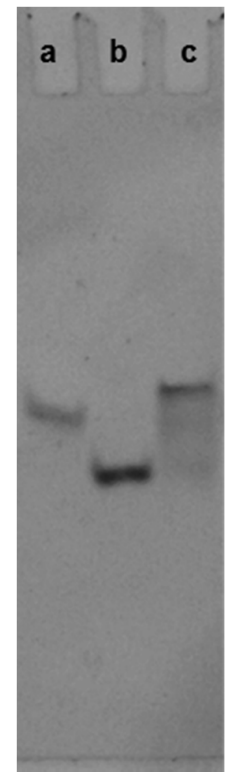

Figure S3. PAGE analysis (18 \% for 100 minutes) utilizing Acryd-DNA and cpDNA. Both DNA were modified with FAM to clearly confirm DNA bands. Lane a; Acryd-DNA, lane b; cpDNA, and lane c; dsDNA of a and b. 
(A)
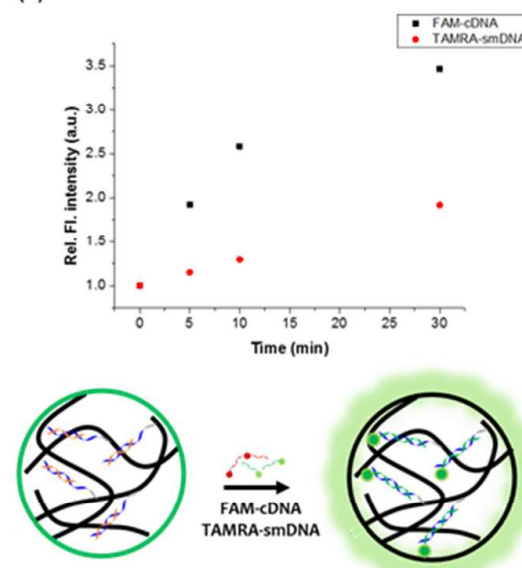

(C)

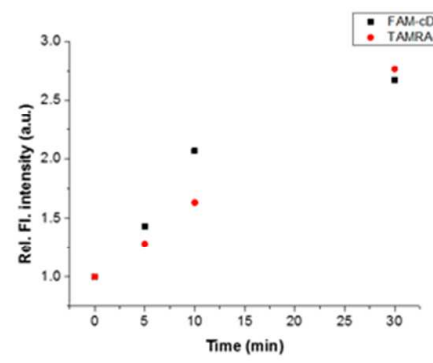

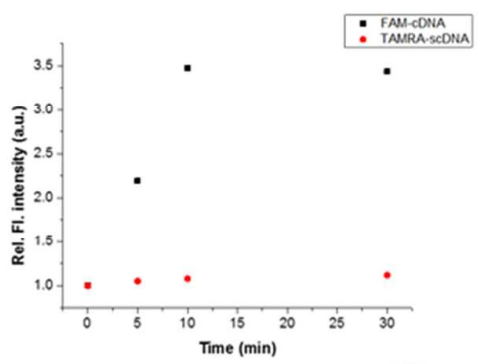

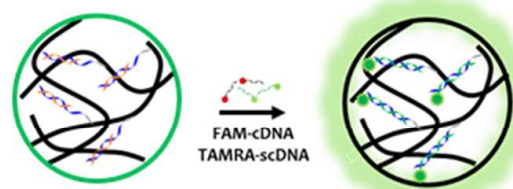

(D)

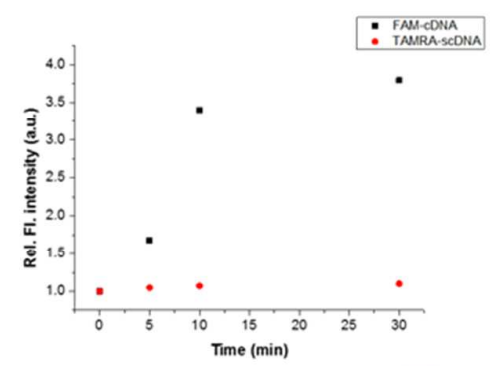

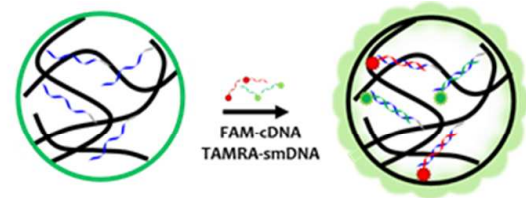
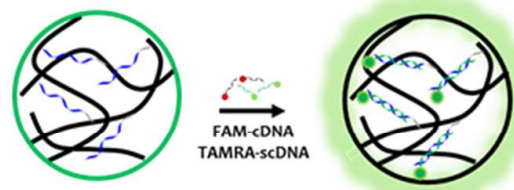

(E)

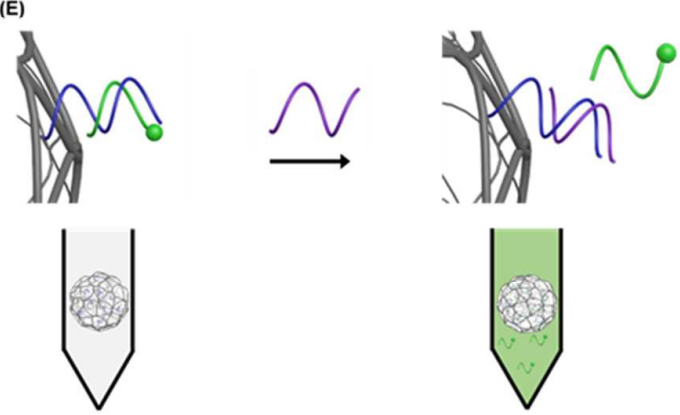

Figure S4. Selectivity test by measuring the fluorescence intensity of remained targetcontaining solution depending on time. The competitor DNA (cpDNA)-conjugated PD-mn was incubated with (A) FAM-cDNA and TAMRA-smDNA mixed solution or (B) FAMcDNA and TAMRA-scDNA mixed solution. The PD-mn without cpDNA was incubated with 
(C) FAM-cDNA and TAMRA-smDNA mixed solution or (D) FAM-cDNA and TAMRAscDNA mixed solution.

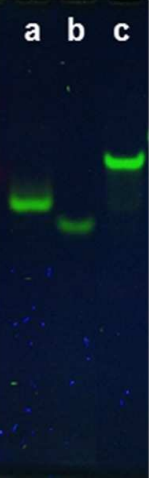

Figure S5. PAGE analysis for ssDNA of Acryd-ATP-DNA (lane a), ATPcpDNA (lane b) and dsDNA of Acryd-ATP-DNA and ATPcpDNA (lane c). The formation of dsDNA was successfully confirmed by lane c.

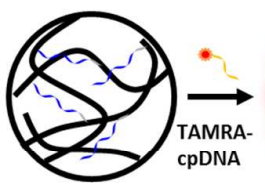

$\left(a_{n}\right)$

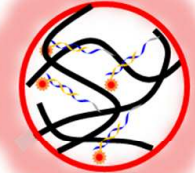

$\left(b_{n}\right)$

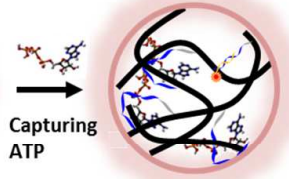

$\left(c_{n}\right)$

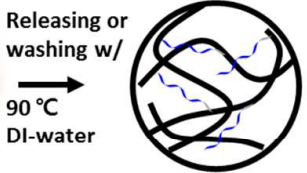

$\left(d_{n}\right)$

Figure S6. Reusability test procedure for ATP capturing of PD-mn. The experimental result is shown in Figure 5. 


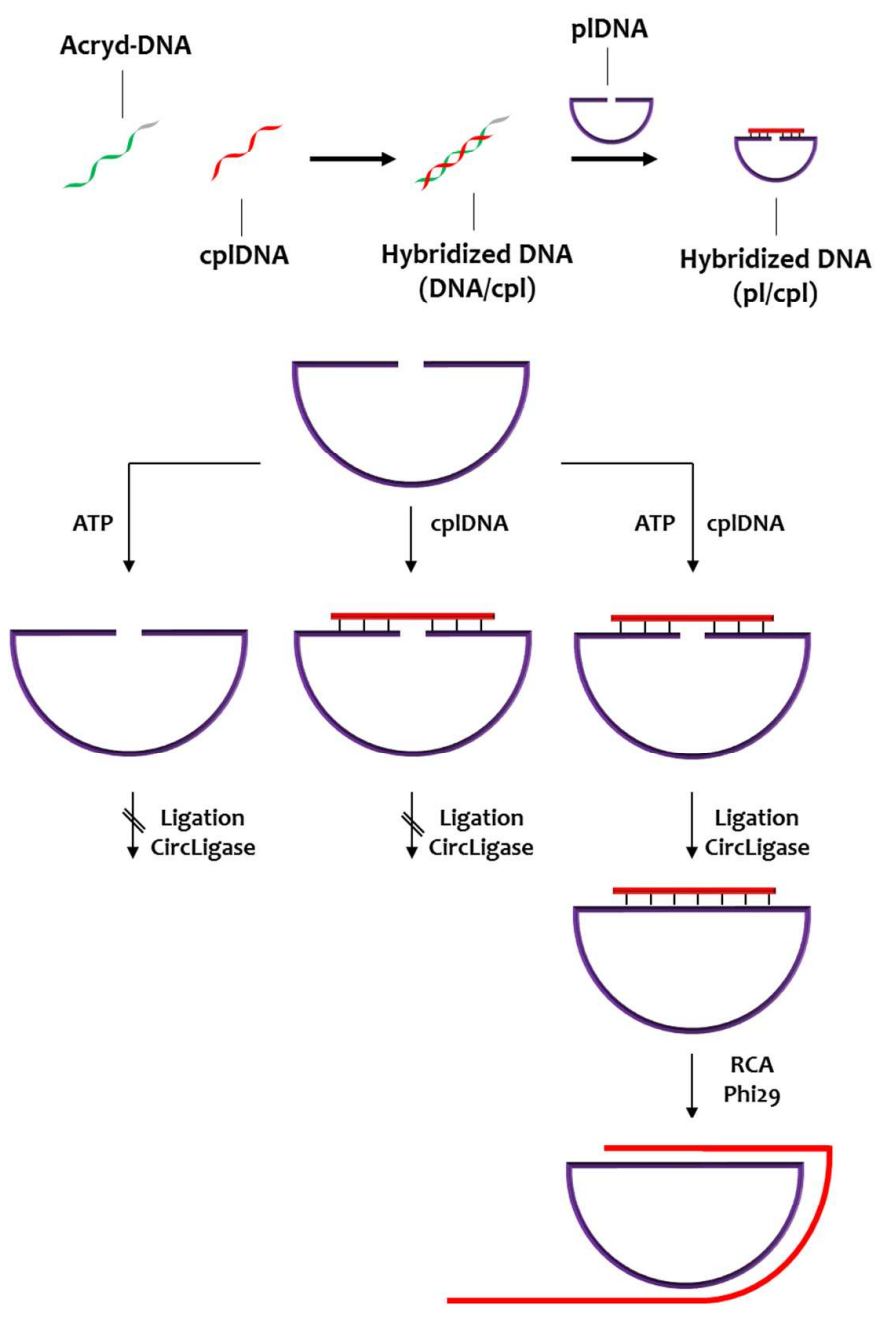

Figure S7. Brief experimental scheme for circularization of padlock DNA (plDNA) and RCA enzymatic reaction. Utilizing both cpIDNA and ATP, RCA reaction was successfully conducted. 


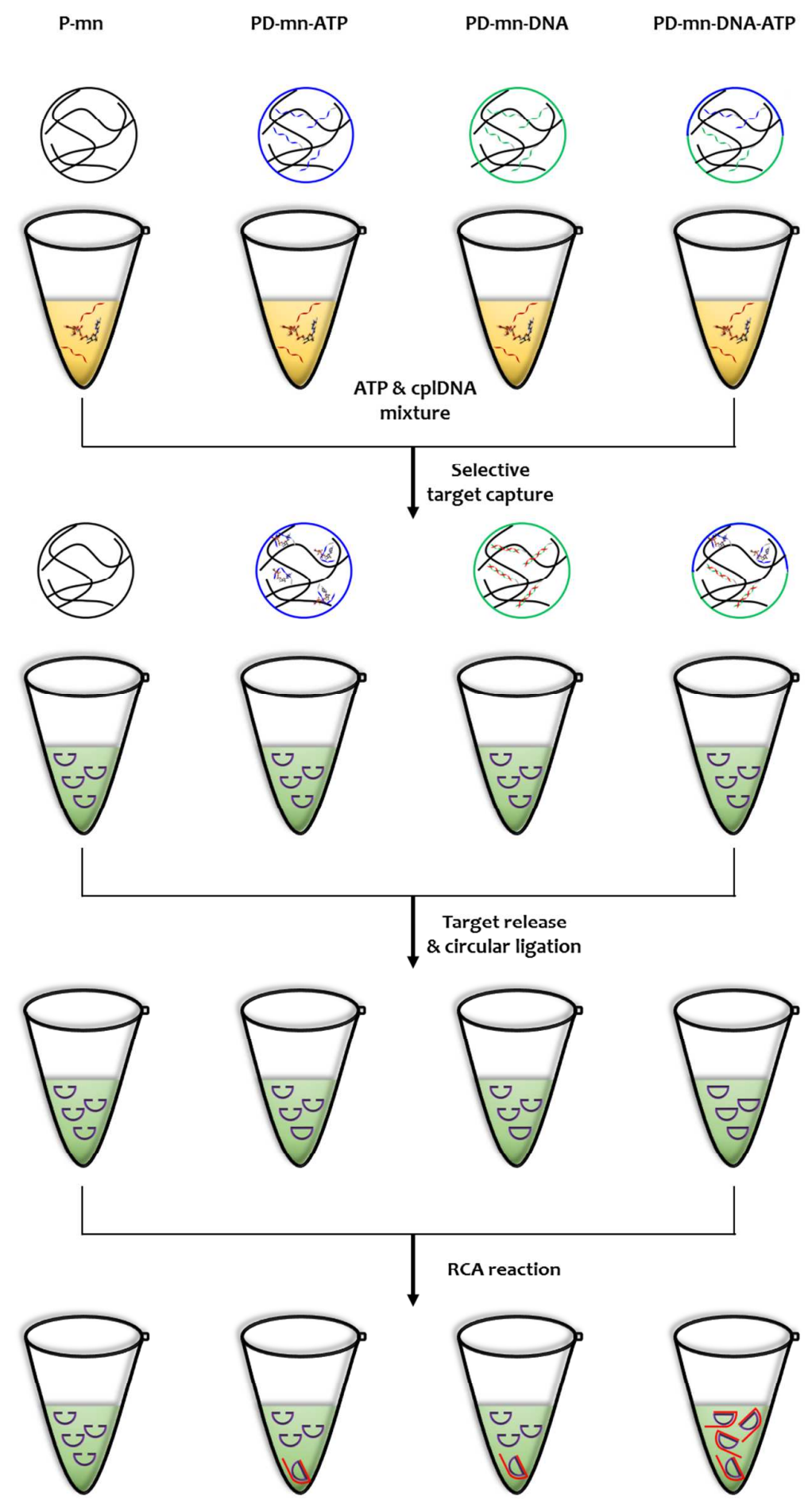

Figure S8. Experimental flow for circularization of DNA and RCA enzymatic reaction utilizing designed PD-mn, PD-mn-ATP, PD-mn-DNA, and PD-mn-DNA-ATP. Before 
proceeding circular ligation, the PD-mn was removed from the reaction solution. The result was shown in Figure 6.

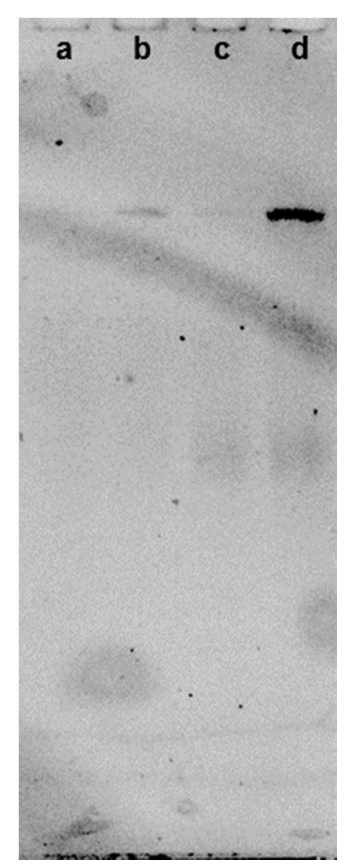

Figure S9. PAGE image test for circularization of plDNA efficiency utilizing plDNA+ligase (lane a), plDNA+ligase+ATP (lane b), plDNA+ligase+cplDNA (lane c), and plDNA + ligase + ATP + cplDNA (lane d) in buffer solution. 


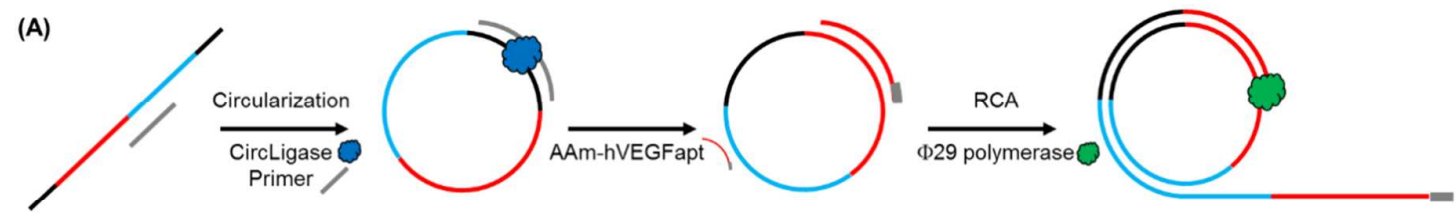

(B)

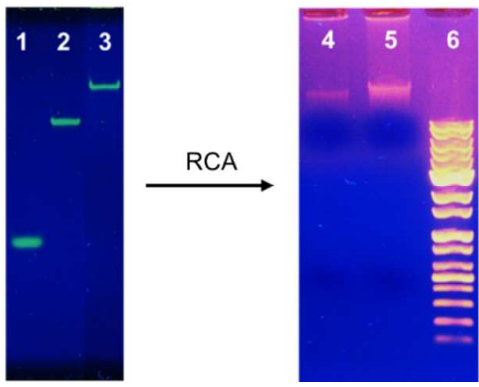

(C)

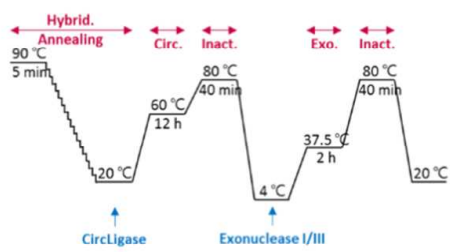

(D)

Figure S10. (A) The circularization reaction and amplification process of DNA for preparation of P-aApt. (B) Confirmation of circularized DNA by PAGE analysis and amplified DNA by agarose gel electrophoresis. Lane 1: Primer, Lane 2: Circ_cVEGF, Lane 3: Circularized Circ_cVEGF, Lane 4: Amplified DNA for $1 \mathrm{~h}$ enzymatic reaction, Lane 5: Amplified DNA for $3 \mathrm{~h}$ enzymatic reaction, Lane 6: DNA ladder from $100 \mathrm{bps}$ to $10 \mathrm{kbps}$. Sequence information is shown in Table S4. (C) Circularization and rolling circle amplification enzymatic processes were shown. 
(A)

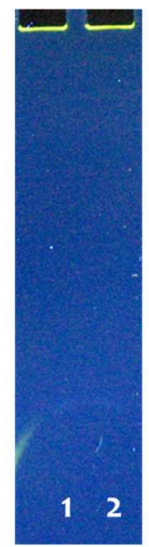

(B)

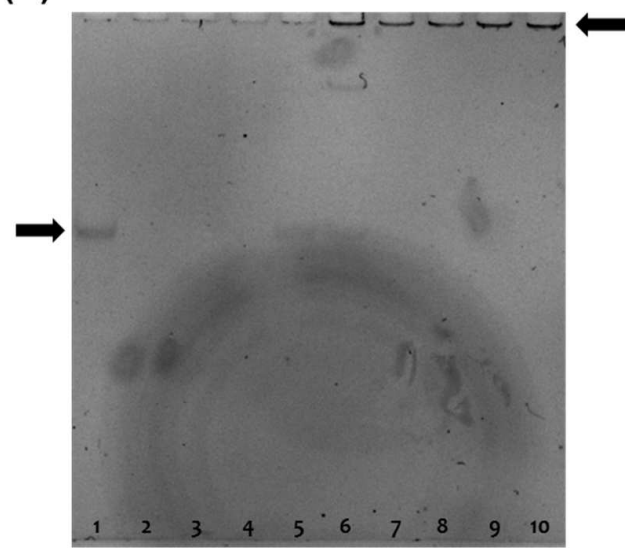

Figure S11. (A) UV light stability of amplified DNA confirmed by PAGE. Lane 1: amplified DNA, Lane 2: amplified DNA after 7 minutes UV irradiation same as P-aApt sheet polymerization time. (B) Enzymatic degradation test for short DNA and amplified DNA using DNase depending on time by PAGE analysis (20 unit of Exonuclease I for 10 pmole of DNA). Only short stranded DNA showed enzymatic degradation after 0.5 day, however amplified DNA did not degraded until 4 day incubation. Lane 1: short DNA, Lane 2: after incubation of short DNA and Exonuclease I with 0.5 day, Lane 3: after incubation of short DNA and Exonuclease I with 1 day, Lane 4: after incubation of short DNA and Exonuclease I with 3 day, Lane 5: after incubation of short DNA and Exonuclease I with 4 day, Lane 6: amplified aptamer, Lane 7: after incubation of amplified DNA and Exonuclease I with 0.5 day, Lane 8: after incubation of amplified DNA and Exonuclease I with 1 day, Lane 9: after incubation of amplified DNA and Exonuclease I with 3 day, Lane 10: after incubation of amplified DNA and Exonuclease I with 4 day. PAGE analysis was conducted utilizing $13 \%$ of polyacrylamide for $1 \mathrm{~h}$ running and staining with $\mathrm{SYBR}^{\circledR}$ Green I. 
(A)

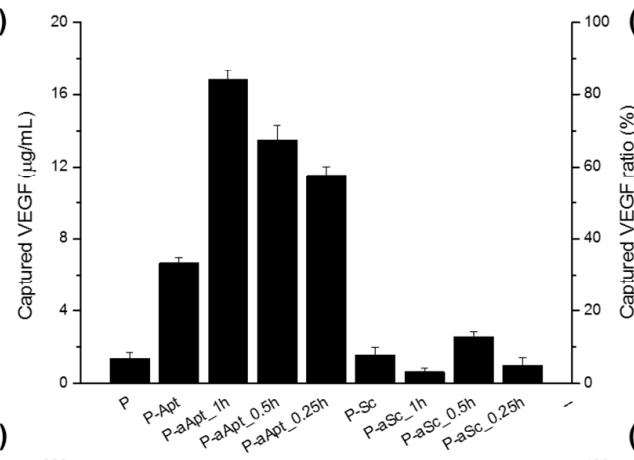

(B)

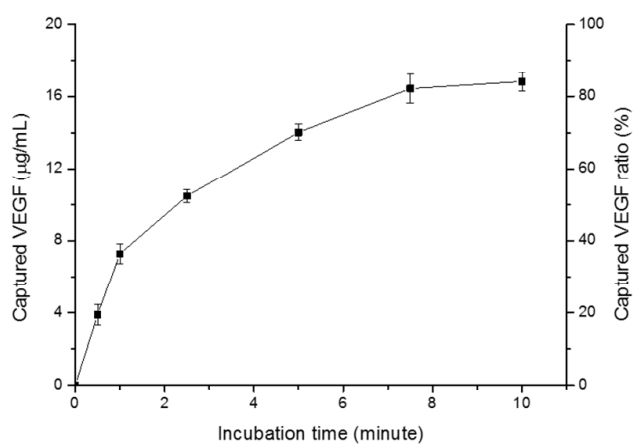

(D)

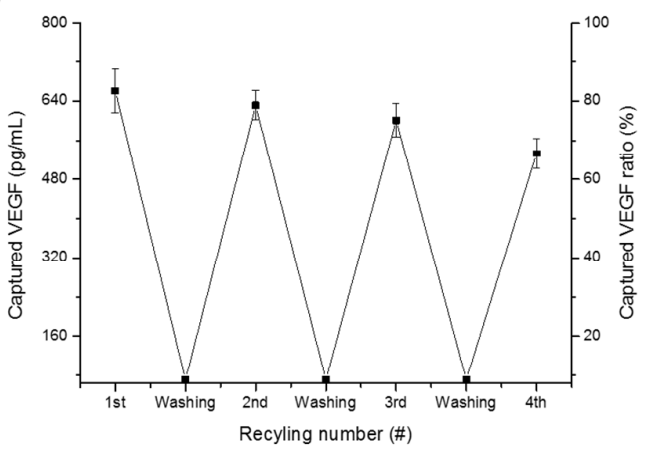

Figure S12. (A) VEGF capture tests for various sheets by Bradford assay with purified VEGF solution (P-aApt_1h means polymer conjugated with aptamer amplified for $1 \mathrm{~h}$ ). The P-aApt sheet series showed high VEGF capturing efficiency depending on amplification time. The sheets were incubated with $20 \mu \mathrm{g} / \mathrm{mL}$ of VEGF solution for 10 minute. Sheets were prepared by 25 pmole of DNA primer. Each sheet was captured VEGF as below; P sheet for $7 \%$, PApt sheet for $33.4 \%$, P-aApt_1h sheet for $84.1 \%$, P-aApt_0.5h sheet for $67.5 \%$, PaApt_0.25h sheet for $57.6 \%$, P-Sc sheet for $7.9 \%$, P-aSc_1h sheet for $3.3 \%$, P-aSc_0.5h sheet for $12.9 \%$ and P-aSc_0.25h sheet for $5.0 \%$. (B) Time dependency of VEGF capturing with P-aApt sheet. Also captured VEGF amount was calculated by Bradford assay. (C) VEGF capture test for various sheets by VEGF ELISA with purified VEGF solution $(800 \mathrm{pg} / \mathrm{mL})$. The P-aApt sheet showed high VEGF capturing efficiency compared to other sheets. The sheets were prepared by 5 pmole of DNA primer. Each sheet was captured VEGF as below; P sheet for $0.8 \%$, P-Apt sheet for $29.6 \%$, P-Sc sheet for $7.7 \%$, P-aApt sheet for $83.5 \%$ and PaSc sheet for $18.0 \%$. (D) Recycling test for P-aApt sheet determined by VEGF ELISA. 


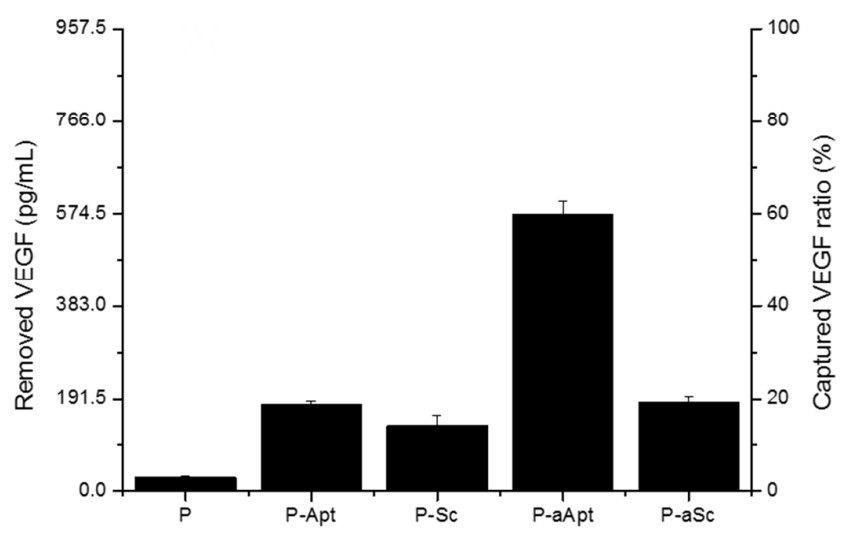

Figure S13. VEGF capturing assay utilizing various sheets in liver hepatocellular carcinoma HepG2 cell line, in vitro. The P-aApt sheet showed high capturing efficiency compared to other sheets. The eluted VEGF by HepG2 cell was measured as $957.55 \mathrm{pg} / \mathrm{mL}$.Each sheet was captured VEGF as below; P sheet for $2.9 \%$, P-Apt sheet for $18.9 \%$, P-Sc sheet for $14.4 \%$, PaApt sheet for $60.0 \%$ and P-aSc sheet for $19.3 \%$. The sheets were prepared by 25 pmole of DNA primer. The P-aApt sheet or P-aSc sheet was prepared by $1 \mathrm{~h}$ amplified DNA. 


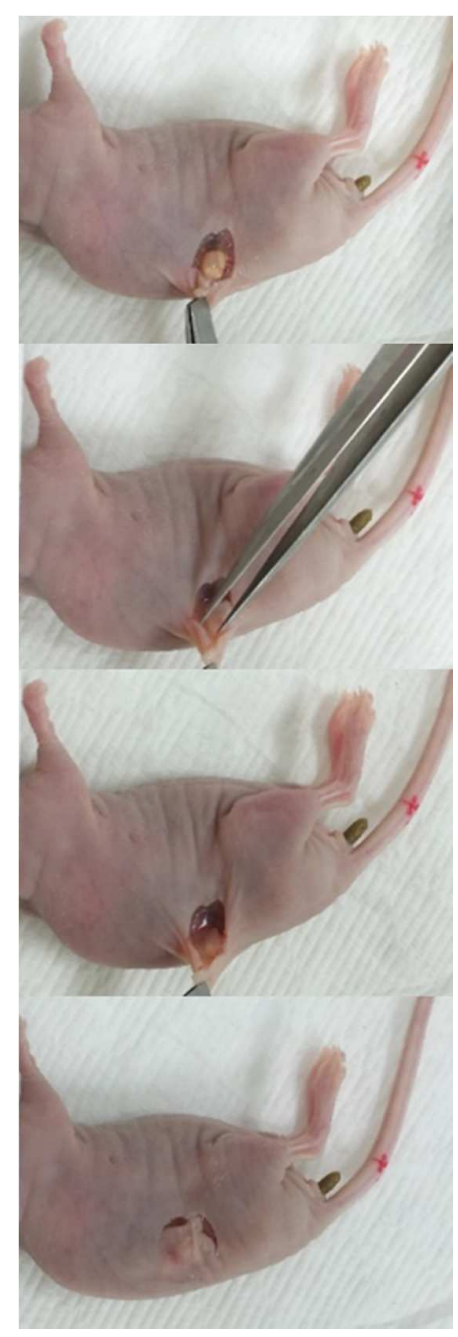

Figure S14. Sheets insertion procedure in vivo. Firstly, the skin on the tumor of etheranesthetized mice was partially cut off. After insertion of two sheets on tumor region, cover the sheets by cut skin and applied a band-aid not to detach the inserted sheets from tumor. The A-549-Luc $\left(10^{8}\right.$ cell/mice for $1^{\text {st }}$ injection and $5 \times 10^{7}$ cell/mice for $2^{\text {nd }}$ injection $)$ xenograft mouse (Balb/c nu/nu female) were utilized. The total number of mouse was 30, which 5 mouse per group. Initial average tumor volume was $45.0 \mathrm{~mm}^{3}$. The sheets were prepared by 25 pmole of DNA primer. The P-aApt sheet or P-aSc sheet was prepared by $1 \mathrm{~h}$ amplified DNA. 
(A)

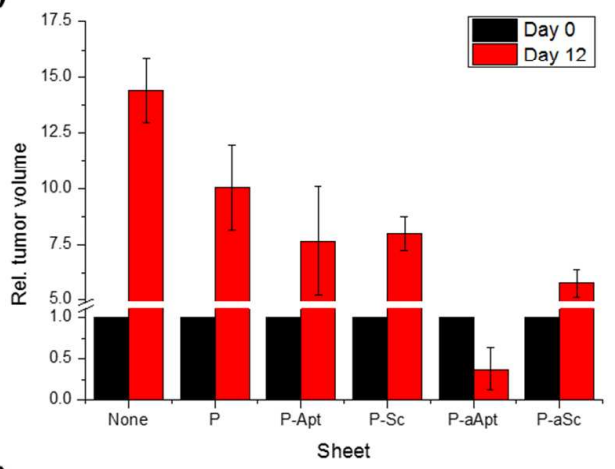

(C)

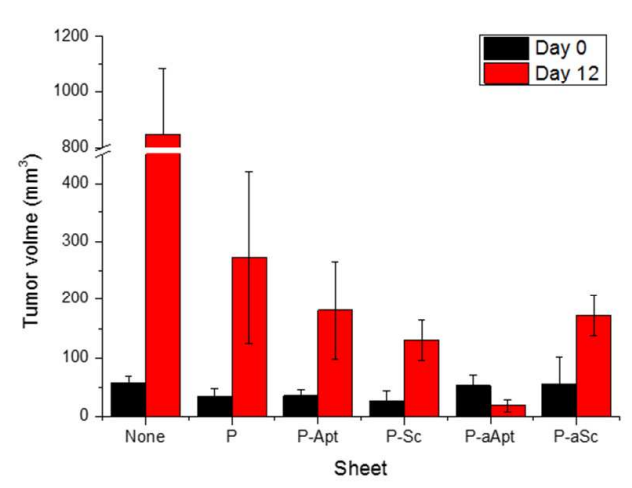

(B)

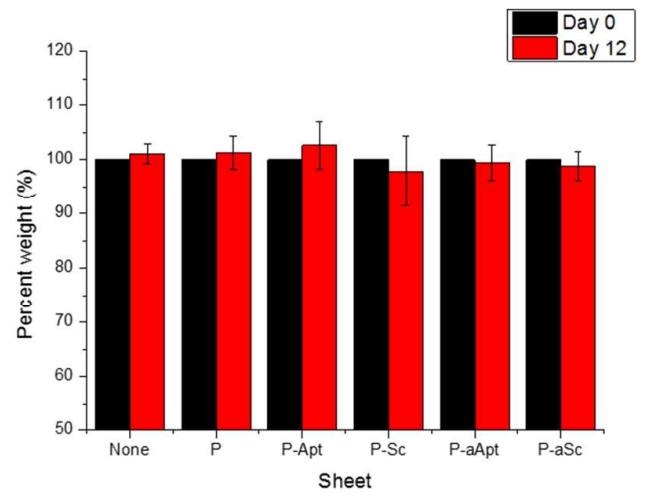

(D)

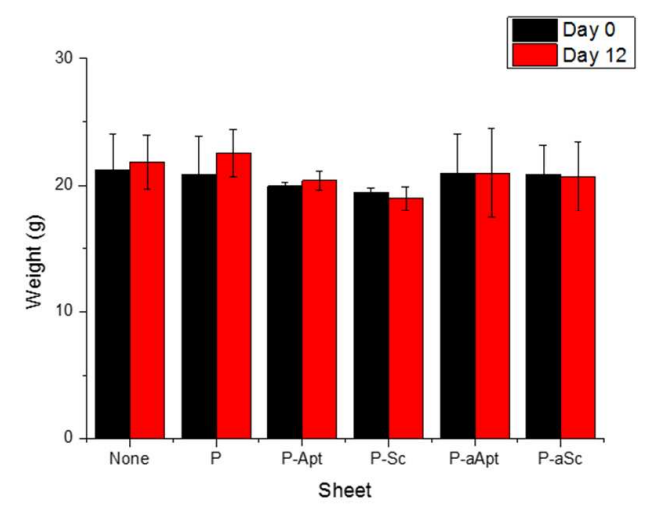

Figure S15. In vivo tumor-bearing mice experiments. Relative A-549-Luc tumor volume (A) and exact A549-Luc tumor volume (C) treated with P P-Apt, P-Sc, P-aApt, P-aSc sheet and no-treated was measured in day 0 and day 12 . The relative mice weight (B) and exact mice weight (D) were measured in day 0 and day 12 . 


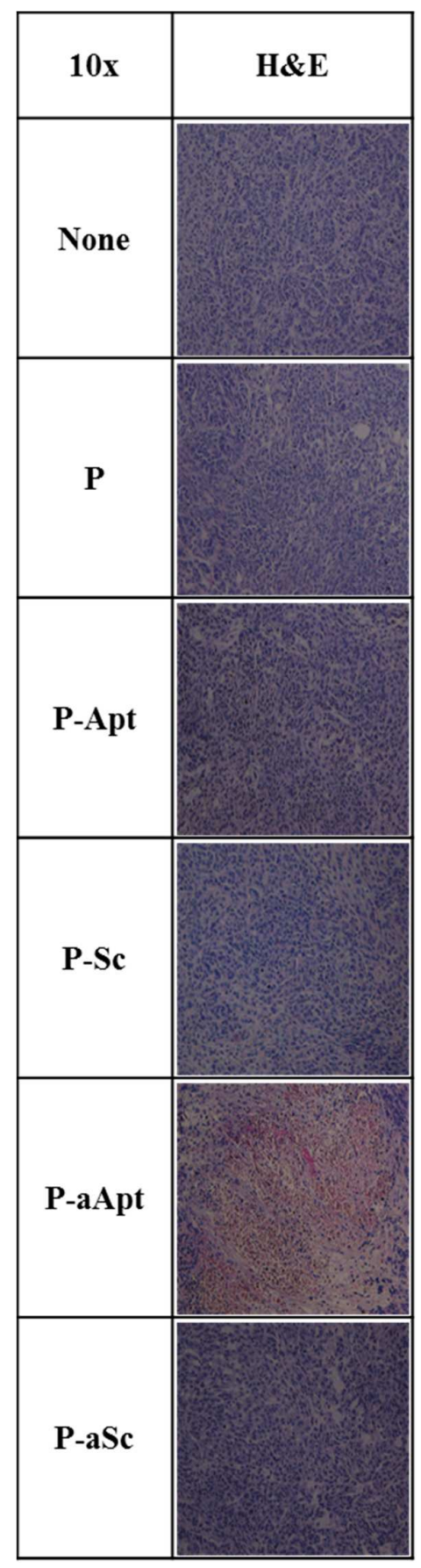

Figure S16. Hematoxylin and eosin $(\mathrm{H} \& \mathrm{E})$-stained sections of the tumor sites of control or treated with P, P-Apt, P-Sc, P-aApt and P-aSc sheet after sacrifice (hematoxylin: blue, eosin: red). Nuclei shows loosely packed manner and meronecrosis is shown in case of P-aApt sheet treated tumor compared to other sheets treated tumors. The images were obtained by $10 \mathrm{x}$ scale. 


\section{References}

(1) Potty, A. S.; Kourentzi, K.; Fang, H.; Jackson, G. W.; Zhang, X; Legge, G. B.; Willson, R. C. Biophysical Characterization of DNA Aptamer Interactions with Vascular Endothelial Growth Factor. Biopolymers, 2009, 91, 145-156. 